\title{
Fabrication of multilayer crystalline rib waveguides by a combined multi-step Pulsed Laser Deposition/precision machining technique
}

\author{
Katherine A. Sloyan, Lewis G. Carpenter, Timothy C. May-Smith, Christopher Holmes, James C. Gates \\ Peter G.R. Smith, Robert W. Eason \\ Optoelectronics Research Centre, University of Southampton, Southampton, UK SO17 1 BJ
}

With low thresholds and high gain, channel and rib waveguide lasers are of interest both as stand-alone devices and as components in integrated optical circuits. A number of approaches may be taken to fabricate such structures, including direct bonding, ion implantation or diffusion and post-processing of deposited films. However, many of these techniques can be prohibitively slow and costly, particularly for rapid prototyping.

Pulsed Laser Deposition (PLD) is a comparatively quick and versatile deposition method that can be used to grow a wide range of materials, including those with complex stoichiometries. One such family of materials are optical garnets, which are of particular interest for laser applications. Many garnets, including $\mathrm{Gd}_{3} \mathrm{Ga}_{5} \mathrm{O}_{12}$ (GGG), have been grown previously via PLD, with high growth rates (microns per hour) and low losses $(<0.1$ $\mathrm{dBcm}^{-1}$ ) [1]. We present a technique that combines PLD with precision sawing (used previously to machine silica-on-silicon cantilevers [2]) to create multilayer crystalline garnet ribs quickly and easily.

A prototype has been fabricated as a proof of concept (see Figure 1). A three-layer structure comprising a Nd:GGG (1 at. \%) layer sandwiched between two layers of undoped GGG was deposited onto a single-crystal $\mathrm{Y}_{3} \mathrm{Al}_{5} \mathrm{O}_{12}$ (YAG) substrate. Each layer was $\sim 1 \mu \mathrm{m}$ in thickness. Pairs of grooves of $\sim 8 \mu \mathrm{m}$ depth and $\sim 6 \mu \mathrm{m}$ width were then cut into the film and substrate using a precision dicing saw. The resulting $\sim 20 \mu \mathrm{m}$ wide, $10 \mathrm{~mm}$ long multilayer ribs were subsequently overgrown via PLD with a further undoped GGG cladding layer. X-ray diffraction analysis of the sample shows that the crystal layers have grown in the epitaxial (100) direction and with a peak FWHM similar to that of the substrate, indicating good crystal quality.

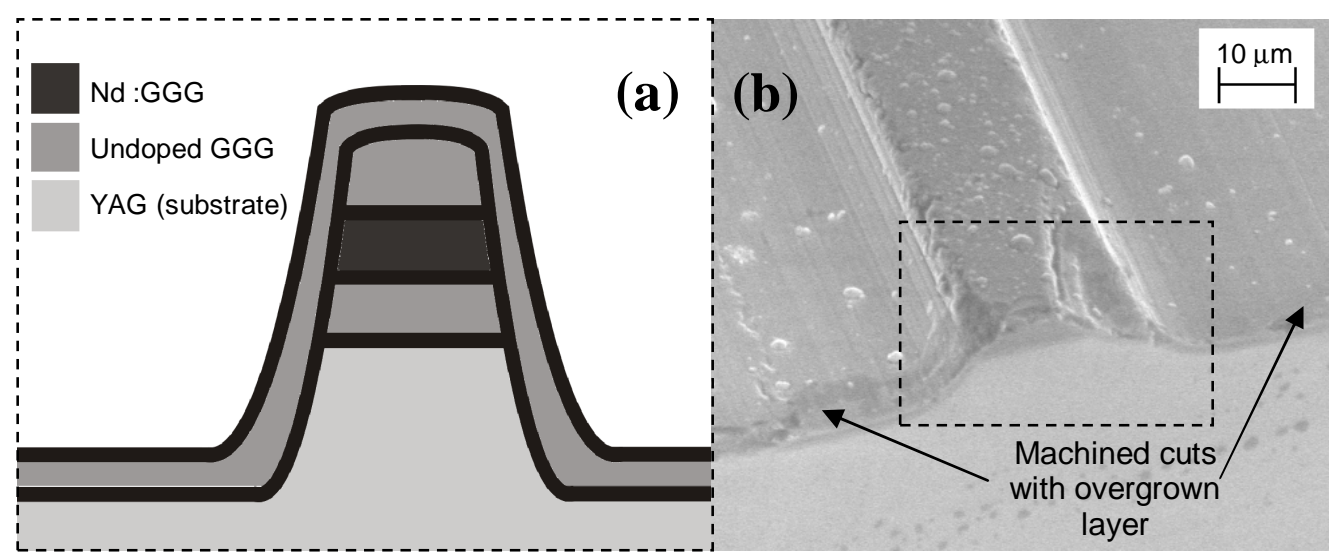

Fig. 1 (a) Cross-section schematic and (b) scanning electron microscope micrograph of a $\sim 20 \mu \mathrm{m}$ wide multilayer rib. A three-layer stack of undoped GGG, Nd-doped GGG and undoped GGG were grown on a YAG substrate, which was then machined using a precision saw. A cladding layer of undoped GGG was overgrown after machining, also via PLD.

Deposition was carried out using a dual-beam, dual-target PLD setup similar to that used by Sloyan et al to grow designer multilayer crystal films, including chirped structures [3]. Stoichiometry control and the ability to engineer physical properties have been reported [4, 5], and the multi-beam approach shows significant promise for graded-layer growth. The potential exists, therefore, for the fabrication of sophisticated rib and channel waveguides and lasers using the combined PLD/precision machining technique detailed above.

Optimal growth conditions for GGG for the current setup are currently being sought, and optimised multilayer ribs will be presented along with the prototype above, as well as a discussion of lasing and graded channel experiments.

\section{References}

[1] T. C. May-Smith, C. Grivas, D. P. Shepherd, R. W. Eason, and M. J. F. Healy, "Thick film growth of high optical quality low loss (0.1 $\left.\mathrm{dB} \mathrm{cm}{ }^{-1}\right) \mathrm{Nd}: \mathrm{Gd}_{3} \mathrm{Ga}_{5} \mathrm{O}_{12}$ on $\mathrm{Y}_{3} \mathrm{Al}_{5} \mathrm{O}_{12}$ by pulsed laser deposition," Appl. Surf. Sci. 223(4), 361-371 (2004).

[2] L. G. Carpenter, C. Holmes, H. L. Rogers, P. G. R. Smith and J. C. Gates, "Integrated optic glass microcantilevers with Bragg grating interrogation" Opt. Express 18(22), 23296-23301 (2010).

[3] K. A. Sloyan, T. C. May-Smith, M. N. Zervas, R. W. Eason, S. Huband, D. Walker, P. A. Thomas, "Growth of crystalline garnet mixed films superlattices and multilayers for optical applications via shuttered Combinatorial Pulsed Laser Deposition" Opt. Express 18(24) (2010). [4] M. S. B. Darby, T. C. May-Smith, R. W. Eason, "Deposition and stoichiometry control of Nd-doped gadolinium gallium garnet thin films by combinatorial pulsed laser deposition using two targets of $\mathrm{Nd}: \mathrm{Gd}_{3} \mathrm{Ga}_{5} \mathrm{O}_{12}$ and $\mathrm{Ga}_{2} \mathrm{O}_{3}$ " Appl. Phys. A 93(2), 477-481 (2008).

[5] R. Gazia, T. C. May-Smith, R. W. Eason, "Growth of a hybrid garnet crystal multilayer structure by combinatorial pulsed laser deposition" J. Cryst. Growth 310(16), 3848-3853 (2008). 